\title{
ENERGY DISSIPATING MODES AND DESIGN RECOMMENDATION OF H-SHAPED STEEL BAFFLES SUBJECTED TO BOULDER IMPACT
}

\author{
Lei Zhao ${ }^{1}$, Li-Jun Zhang ${ }^{1}$, Zhi-Xiang Yu ${ }^{1, *}$, Jian-Wei He ${ }^{2}$ and Xin Qi ${ }^{1}$ \\ School of Civil Engineering, Southwest Jiaotong University, Chengdu, China \\ ${ }^{2}$ Department of Civil and Environmental Engineering, The Hong Kong Polytechnic University, Hong Kong, China \\ *(Corresponding author: E-mail: yzxzrq@switu.edu.cn)
}

\section{A B S T R A C T}

Flexible barriers are one of the most effective protective structures, which have been widely used for the mitigation of rockfalls. As the only compression members in a flexible barrier system, steel posts maintain the integrity of the interception structure to keep the function of the system. Due to the random trajectories of rockfalls, steel posts may be impacted by boulders directly. The impact scenario may result in the failure of the post and even the collapse of the system. In this paper, firstly, steel baffles were proposed to be an additional structural countermeasure to avoid the direct impact of posts. Secondly, numerical method was adopted to study the structural behaviour of steel baffles under direct boulder impact. Then, an available published experimental test of $\mathrm{H}$-shaped steel beams under drop weight impact loading by others was back analyzed to calibrate the finite element model. Finally, numerical simulations were carried out to investigate the energy dissipating modes and energy dissipating efficiency of the H-shaped steel baffles. The simulation results show that there are three typical energy dissipating modes of $\mathrm{H}$-shaped baffles subjected to boulder impact, namely flexural, local compression buckling and shear buckling. Local compression buckling is the most efficient energy dissipating mode. The thickness of the web of an $\mathrm{H}$-shaped baffle is suggested to be $4 \mathrm{~mm}$ and $6 \mathrm{~mm}$ for the rated dissipating energy of $50 \mathrm{~kJ}$ and $100 \mathrm{~kJ}$, respectively.
A R T I C L E H I S T O R Y

$\begin{array}{ll}\text { Received: } & \text { 22 December } 2020 \\ \text { Revised: } & \text { 10 April 2021 } \\ \text { Accepted: } & \text { 15 May 2021 }\end{array}$

\section{K E Y W O R D S}

Steel baffle;

Flexible barrier;

Boulder impact;

Energy dissipating mode;

Design recommendation;

Numerical simulation

\section{Introduction}

The function of flexible barriers is similar to that of spider orb webs (Fig 1a), which is to absorb the kinetic energy of the impact while minimizing structural damage. Benefiting from the weight of material, cost, ease and speed of construction, aesthetics and favourable environmental effect, flexible barriers are the most effective protective structures and have been extensively used for the mitigation of rockfalls [1-6] in hilly regions. In addition to footings, a typical flexible barrier (Fig. 1b) is mainly composed of three parts: 1) an interception structure; 2) a support structure; 3 ) connection components [7]. The interception structure is usually made up of cable nets or ring nets and bears the direct impact of the rockfall, transmitting the stresses to the connection components. A support structure usually consists of steel posts and maintains the interception structure erected through the connection components. The connection components include support ropes, anchor ropes and shackles, etc. They transmit the impact loads to the footing structure and then to the ground. They also help to maintain the integrity of the interception structure. Energy dissipating device is the most critical component in the system, dissipating around $60 \%-80 \%$ of the total impact energy [8] through friction between components, plastic deformation or their combination [9]. As energy dissipating devices are attached to steel ropes and allowed for a controlled displacement after activation, they are usually classified as a connection component.

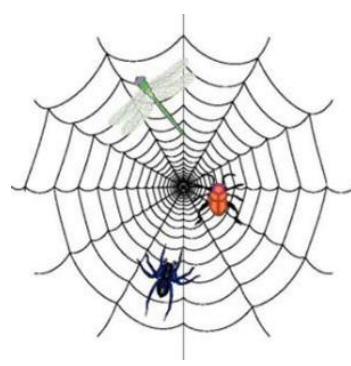

(a) Spider orb web

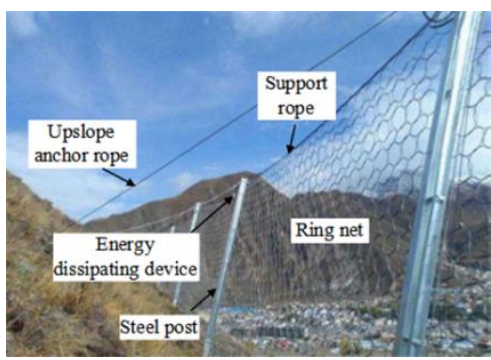

(b) Flexible rockfall barrier
Fig. 1 Typical flexible barrier

As the support structure in a flexible barrier, steel posts ensure the position of the interception structure and the function of the system. From the view of stress characteristics, steel posts are the only compression members in the system, and all the other components are in tension during interception.
The stress characteristic of flexible barriers is similar to tensegrity structures, figuratively described as "small islands of compression in a sea of tension" [10]. Due to the random trajectories of rockfalls [11], steel posts may be impacted by boulders directly which may result in the failure of the post and even the collapse of the system [1,12,13]. Field investigations (Fig. 2) also show that the failure of steel posts due to the direct impact of boulders happened occasionally. To solve this problem, it is necessary to improve the impact resistance of steel posts of flexible barrier or reduce the impact energy of the boulder or even avoid the scenario that boulders directly impact on steel posts.
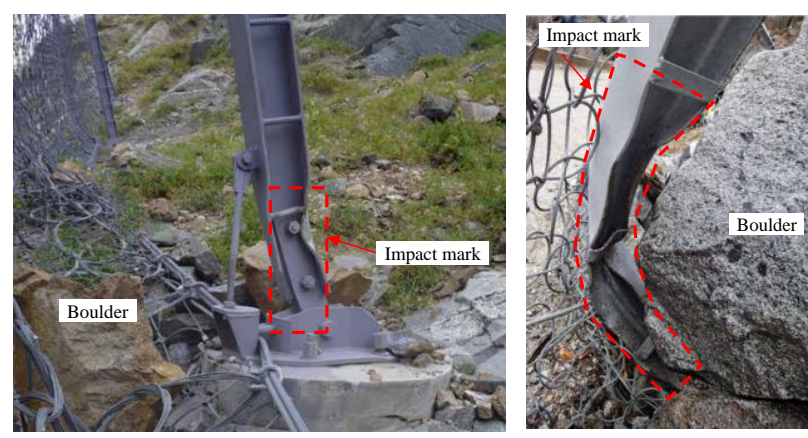

Fig. 2 Steel post directly impacted by boulders [14]

In this paper, firstly, steel baffles, as a straining structure, were proposed to be an additional structural countermeasure installed in front of the steel posts of flexible barriers to protect the steel posts from boulder impact in Section 2, and the principle of the baffles was also discussed in the section. Then, an available published experimental test of $\mathrm{H}$-shaped steel beams under drop weight impact loading by others was back analyzed in Section 3. The test results of contact force and lateral deflection were used to calibrate the finite element model. Finally, numerical simulations were carried out to investigate the energy dissipating modes and energy dissipating efficiency of the $\mathrm{H}$ shaped steel baffles in Section 4.

\section{Principle of the baffle}

The impact resistance of the steel post can be improved by increasing the section size. However, this measure will significantly increase the weight of the steel post and bring difficulties in field construction. Besides, the enhanced steel post is still the first and only line of defense against the direct 
impact of a boulder which is not conducive to improving the reliability of flexible barrier systems.

The concept of multiple lines of defense has been widely accepted and adopted in structural seismic design [15]. Based on this concept, a baffle is proposed to be installed in front of the post to be the first line of defense. Instead of the protected post, the baffle will bear the first direct impact of boulders which could have impacted the post directly. After impacting the baffle, the kinetic energy of the boulder will be reduced significantly, owing to the plastic deformation of the baffle, damping or additional energy dissipating device. By trapping boulders upstream, the impact load can be reduced for the post of a flexible barrier in the downstream. In addition, the trajectory of the boulder will be changed, the boulder will impact the interception structure of the flexible barrier rather than the downstream post. In summary, the principle of the baffle mainly lies in the following two aspects: a) dissipate the impact energy of the boulder; b) change the trajectory of the boulder.

In essence, the baffle is a cantilever post subjected to impact load. Shaped steel is suggested to be used, such as H-shaped steel, circular tube and square tube. Concrete-filled steel tube (CFST) is also a good choice. Therefore, the baffles are light-weight and can be easily transported and constructed on a relatively steep terrain with poor access. The site of the baffle is certainly in front of the post to be protected. The height and the capacity of a baffle mainly depend on the bounce height and the kinetic energy of the boulder, respectively, which can be predicted by the movement analysis of rockfalls. In general, the height of the baffle is smaller than the protected post.
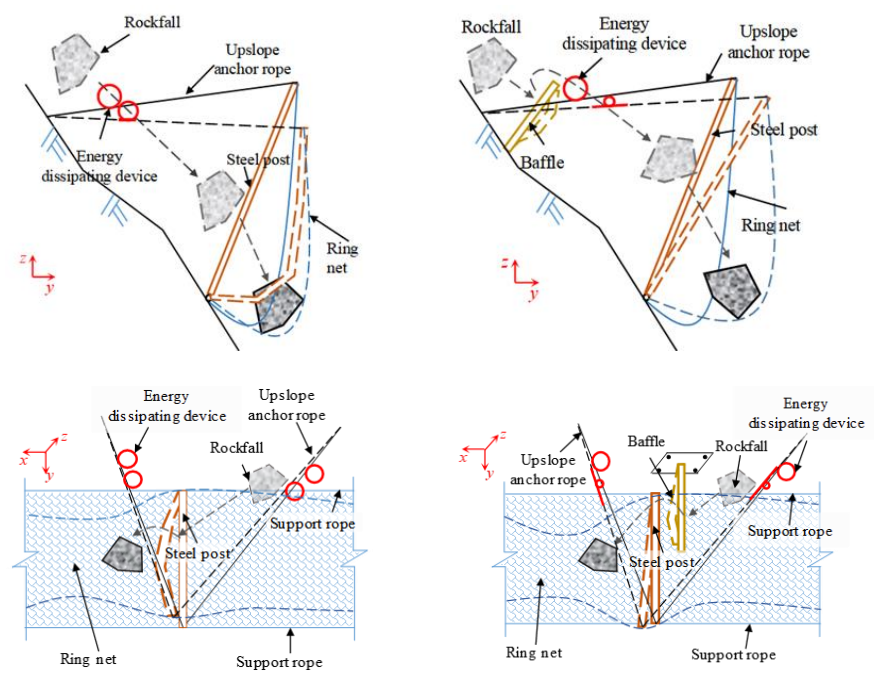

(a)Without baffle

(b) With baffle

Fig. 3 Principle of the baffle

\section{Validation of the numerical model}

A considerable amount of literature has been published on studies of the dynamic behaviour and failure modes of steel members under the transverse impact. In particular, the behaviour of axially restrained beams and axially compressed steel columns has been studied extensively and intensively [1620]. This is understandable since axially restrained beams and axially compressed steel columns are frequently used as members in buildings and bridges, etc. Obviously, the behaviour of cantilever posts under transverse impact will be different, and the related studies are few. Consequently, there is insufficient data to understand the dynamic behaviour of the baffle subjected to boulder impact.

As there is no available test data of baffles or cantilever steel posts under transverse impact, in this section, a published experimental test of a series of $\mathrm{H}$-shaped steel beams under drop weight impact loading by others will be back analyzed to calibrate the LS-DYNA model.

\subsection{Description of the test}

The experimental test for calibration was conducted by Zhao et al. [19]. The specimens were with fixed-pinned (FP) end condition. Two square end plates with a thickness of $16 \mathrm{~mm}$ were welded to each specimen. The length of each specimen was $1.5 \mathrm{~m}$, and the section was $h \times b \times t_{\mathrm{w}} \times t_{\mathrm{f}}=100 \times 100 \times 6 \times 8 \mathrm{~mm}$. The beam was impacted at the midpoint by a hammer. The hammer is made of GCr 15 steel with $64 \mathrm{HRC}$ hardness and a $30 \mathrm{~mm} \times 80 \mathrm{~mm}$ rigid bottom surface. The experimental setup is shown in Fig. 4 as well as the details of steel beams and the LS-DYNA back-analysis model. In the test, the impact forces were monitored and recorded by a dynamic load cell. The details of the H-shaped steel specimens are illustrated in Table 1.

Table 1

Details of H-shaped specimens [19]

\begin{tabular}{cccccc}
\hline Case & Specimen label & $m_{0}(\mathrm{~kg})$ & $H_{0}(\mathrm{~m})$ & $v_{0}(\mathrm{~m} / \mathrm{s})$ & $E_{0}(\mathrm{~kJ})$ \\
\hline 1 & H-0.9-FP & 89 & 1.04 & 4.5 & 0.9 \\
2 & H-2.5-FP & 150 & 1.67 & 5.7 & 2.5 \\
3 & H-2.9-FP & 150 & 2 & 6.2 & 2.9 \\
4 & H-3.7-FP & 150 & 2.5 & 7.0 & 3.7 \\
\hline
\end{tabular}

Note: $m_{0}$ is the weight of the hammer, $H_{0}$ is the hammer release height; $E_{0}$ is the impact energy before collision; $v_{0}$ is the initial impact velocity of the hammer.



(a) Drop-hammer machine

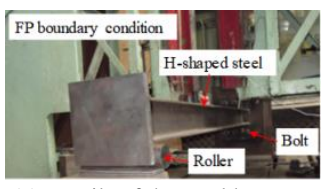

(c) Details of the steel beam

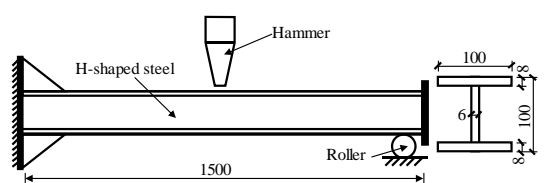

(b) Experimental setup

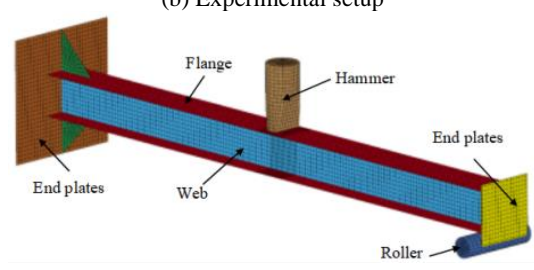

(d) LS-DYNA model
Fig. 4 Experimental setup of Zhao et al. [19]

\subsection{Description of LS-DYNA model}

Considering the thickness of the $\mathrm{H}$-section is much smaller than the other two dimensions, the default shell element named Belytschko-Lin-Tsay element, which is computationally efficient and stable for explicit calculations, was selected for modelling the beams. A five-stage elastic-plastic model developed by Han et al. [21] was employed to simulate the steel material. The model includes the elastic, elastic-plastic, plastic, hardening and secondary plastic flow stages, as presented in Fig. 5. Referring to the tests conducted by Zhao et al. [19], the following parameters were used: the density was $7850 \mathrm{~kg} / \mathrm{m}^{3}$, the modulus of elasticity was $211 \mathrm{GPa}$, Poisson's ratio was 0.3 , yield stress was $291.3 \mathrm{MPa}$, the tangent modulus was $1.476 \mathrm{GPa}$ and the failure strain was 0.284 . Additionally, the Cowper-Symonds model [22] was adopted to scale the yield stress by a strain rate dependent factor, as shown in Eq. (1):

$\sigma_{\mathrm{yd}}=\sigma_{\mathrm{ys}}\left[1+\left(\frac{\& \mathrm{k}}{C}\right)\right]^{\frac{1}{P}}$

where $\sigma_{\mathrm{yd}}$ and $\sigma_{\mathrm{ys}}$ are the dynamic yield stress of steel under the stress rate and the static yield stress, respectively; $C$ and $P$ are the strain rate parameters with values $40.4 \mathrm{~s}^{-1}$ and 5 according to the summary of Jones [23], respectively.

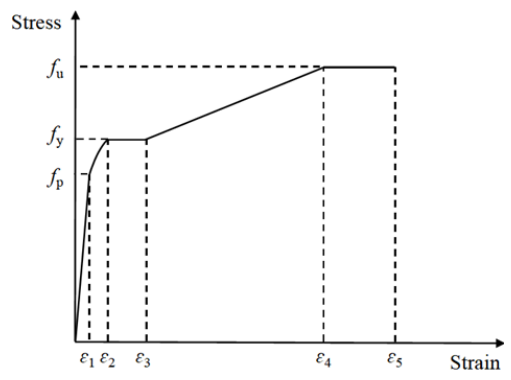

Fig. 5 Five-stage elastic-plastic model 
The hammer and the roller were modelled by the default constant stress solid element. As the deformations of the hammer and the roller were very small during the impact process, they were defined as rigid bodies to reduce the computational requirement. The neglect of the deformations only has little influence on the impact results.

The mesh size will affect the computational cost and accuracy. A reasonable mesh size means that the computational accuracy is satisfactory and the computational cost is acceptable. When the mesh is too fine, the computational cost will increase significantly, but the computational accuracy will not be improved noticeably. When the mesh is too rough, the computational cost will decrease, but the accuracy will also be decreased. By trial and error, the mesh size was selected to be $5 \mathrm{~mm}$ at the impact zone and $10 \mathrm{~mm}$ at other zones.

An automatic surface-to-surface contact algorithm (Contact_Automatic_ Surface_To_Surface in LS-DYNA) [24] was adopted to simulate the contact behaviour between the hammer and the steel beam, as well as the beam and the roller. In the test, the hammer dropped freely from a specified height, but it was positioned above the top flange of the beam with an equivalent initial velocity to reduce the computer time in the model.

\subsection{Calibration of LS-DYNA model}

Fig. 6 compares the local deformations at the midspan zone. It can be seen that the simulated deformed shapes agree well with the test. The local deformations are mainly concentrated on the midspan and minor buckling in the web occurs. Fig. 7 compares the experimental and numerical impact forcetime relationships. The test results and the simulation results, including the peak impact forces $\left(F_{\text {peak }}\right)$, the plateau impact forces $\left(F_{\text {plateau }}\right)$, and the durations of impact force $(T)$ are presented in Table 2. For Cases 1 to 4 , the maximum error of experimental and numerical results is $19.2 \%$, which occurs at the peak impact force in Case 1. It can be seen that both the impact force and the durations all agree very well.

As a conclusion, it may be accepted that the present LS-DYNA model with the associated material behaviour is capable of simulating the behaviour of steel members subjected to impact loading.



(a) Experimental result

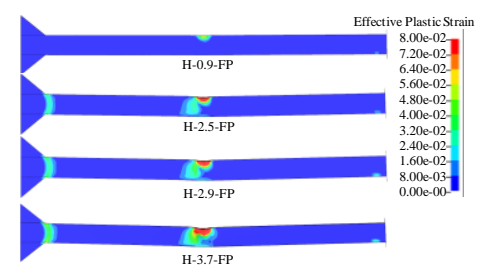

(b) Numerical result

Fig. 6 Comparison of the local deformation shape

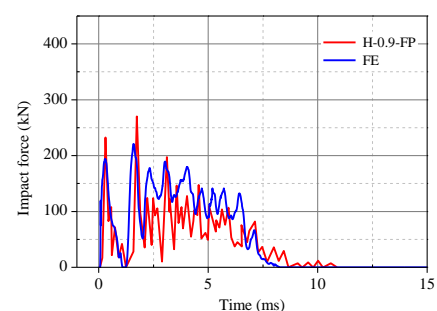

(a) Case 1



(c) Case 3

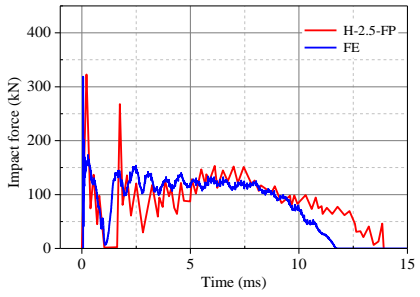

(b) Case 2

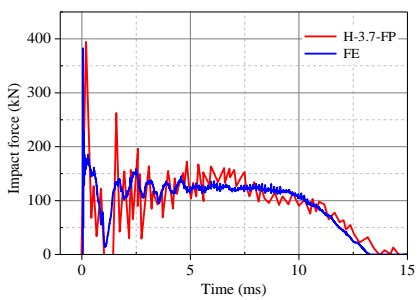

(d) Case 4

Fig. 7 Comparison of the impact force

Table 2

Comparison of the results

\begin{tabular}{|c|c|c|c|c|c|c|c|c|c|c|}
\hline \multirow{2}{*}{ Case } & \multirow{2}{*}{ Specimen label } & \multicolumn{2}{|c|}{$F_{\text {peak }}(\mathrm{kN})$} & \multirow{2}{*}{$\begin{array}{l}\text { Error } \\
(\%)\end{array}$} & \multicolumn{2}{|c|}{$F_{\text {plateau }}(\mathrm{kN})$} & \multirow{2}{*}{$\begin{array}{l}\text { Error } \\
(\%)\end{array}$} & \multicolumn{2}{|c|}{$T(\mathrm{~ms})$} & \multirow{2}{*}{$\begin{array}{c}\text { Error } \\
(\%)\end{array}$} \\
\hline & & Tested & $\mathrm{FE}$ & & Tested & $\mathrm{FE}$ & & Tested & $\mathrm{FE}$ & \\
\hline 1 & $\mathrm{H}-0.9-\mathrm{FP}$ & 239.9 & 193.7 & 19.2 & 122.8 & 133.5 & 8.7 & 10.1 & 8.26 & 18.2 \\
\hline 2 & $\mathrm{H}-2.5-\mathrm{FP}$ & 324.0 & 318.5 & 1.7 & 141.1 & 125.2 & 11.3 & 13.8 & 11.7 & 15.2 \\
\hline 3 & H-2.9-FP & 422.5 & 348.9 & 17.4 & 143.4 & 126.3 & 11.9 & 14 & 12.3 & 12.1 \\
\hline 4 & H-3.7-FP & 399.2 & 382.4 & 4.2 & 158.9 & 129.7 & 18.4 & 14.3 & 13.2 & 7.7 \\
\hline
\end{tabular}

\section{Dynamic response}

\subsection{Modelling properties}

$\mathrm{H}$-shaped baffles with a height of $2.0 \mathrm{~m}$ were used to reveal the energy dissipating modes of an H-shaped steel baffles subjected to boulder impact. The same LS-DYNA simulation method calibrated in the previous section was used. It should be mentioned that the steel grade was assumed to be Q235 [25] and the yield strength was assumed to be a standard value of $235 \mathrm{MPa}$. The full-frontal impact was applied to the flanges (Point $\mathrm{P}$ in Fig. 8) to cause bending about the major axis ( $\mathrm{x}-\mathrm{x}$ axis) of the baffle, which represents the most typical case for design purposes. The impact point was assumed to be $0.8 \mathrm{~m}$ away from the top of the baffle. The bottom of the baffle was fixed end condition. A side-view schematic of the model is shown in Fig. 8.

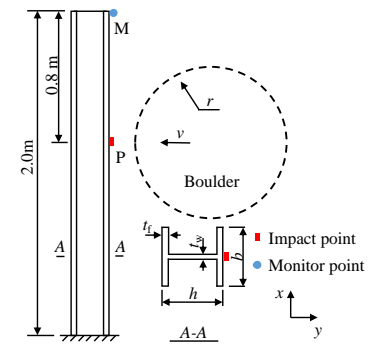

\subsection{Simulation case}

According to the elastic mechanic, the critical stress of a steel plate can be uniformly expressed as Eq. (2):

$\sigma_{\mathrm{cr}}=\chi k \frac{\pi^{2} E}{12\left(1-v^{2}\right)}\left(\frac{t}{b}\right)^{2}$

where $\chi$ is the constraint coefficient, $k$ is the buckling coefficient, $E$ and $v$ are the modulus of elasticity and Poisson's ratio of steel, $t$ and $b$ are the thickness and width of the plate, respectively.

From Eq. (2), it can be seen that either the flange or the web of an $\mathrm{H}$ shaped baffle, the critical stress of which mainly depends on the ratio of thickness and width of the plate. In other words, the energy dissipating mode of a baffle subjected to the impact of a boulder may mainly depend on the flange width-thickness ratio and the web depth-thickness ratio, denoted by $\gamma_{\mathrm{f}}$ and $\gamma_{\mathrm{w}}$, respectively. From this point of view, three typical cases as shown in Table 3 were conducted. In these cases, the depth and width of these cross sections both were fixed to $300 \mathrm{~mm}$. The thickness of the flange and web were carefully chosen to obtain different combinations of $\gamma_{\mathrm{f}}$ and $\gamma_{\mathrm{w}}$. In these cases, the boulder was $1.2 \mathrm{~m}$ in diameter and about $2000 \mathrm{~kg}$ in mass. The boulder impacts at point $\mathrm{P}$ as shown in Fig. 8 with the initial velocity of $10 \mathrm{~m} / \mathrm{s}$. So, the impact energies $\left(E_{0}\right)$ of these cases all were $100 \mathrm{~kJ}$. 
Table 3

Typical cases of energy dissipating mode

\begin{tabular}{ccccccc}
\hline \multirow{2}{*}{ Case } & \multicolumn{3}{c}{ Cross-section properties } & \multicolumn{3}{c}{ Impact properties } \\
\cline { 2 - 7 } & Size & $\gamma_{\mathrm{f}}$ & $\gamma_{\mathrm{w}}$ & $m(\mathrm{~kg})$ & $v_{0}(\mathrm{~m} / \mathrm{s})$ & $E_{0}(\mathrm{~kJ})$ \\
\hline Case-1 & $\mathrm{H} 300 \times 300 \times 12 \times 12$ & 12.5 & 23.0 & 2000 & 10.0 & 100 \\
Case-2 & $\mathrm{H} 300 \times 300 \times 6 \times 12$ & 12.5 & 46.0 & 2000 & 10.0 & 100 \\
Case-3 & $\mathrm{H} 300 \times 300 \times 6 \times 25$ & 6.0 & 41.7 & 2000 & 10.0 & 100 \\
\hline
\end{tabular}

\subsection{Simulation results}

\subsubsection{Impact force}

The velocity-time histories of these boulders (Fig. 9) show that the boulders rebound with $1.2 \mathrm{~m} / \mathrm{s}, 1.3 \mathrm{~m} / \mathrm{s}$ and $1.4 \mathrm{~m} / \mathrm{s}$ in velocity for Case 1 to Case 3 after the impact, which means that all the baffles withstood the frontal impact of the boulder with $100 \mathrm{~kJ}$ in kinetic energy successfully. The impacts last about $55 \mathrm{~ms}, 99 \mathrm{~ms}$ and $65 \mathrm{~ms}$ for Case 1 to Case 3, respectively.

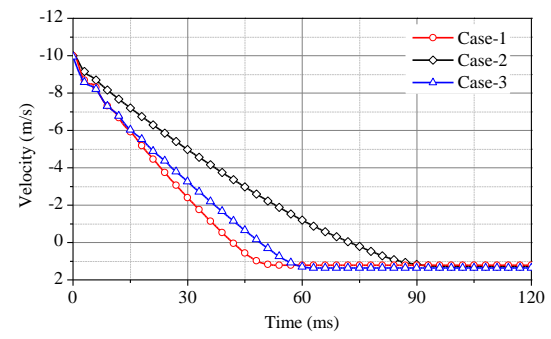

Fig. 9 Velocity-time history of boulder

The impact force-time histories (Fig. 10) of these cases are similar. All of them show the same characteristic of three stages, named peak stage $\left(S_{1}\right)$, stable stage $\left(\mathrm{S}_{2}\right)$ and unload stage $\left(\mathrm{S}_{3}\right)$, respectively. In the peak stage, the interaction between the boulder and impact area of the baffle increases rapidly due to the transient action of the impact and the big local stiffness of the impact area, resulting in the maximum peak impact force at the first impact. As the mass of the boulder is much bigger than that of the baffle, the velocity of the baffle increases rapidly, but the velocity of the boulder decreases. The interaction between boulder and baffle becomes weaker, resulting in a rapid decrease of the impact force. Then, the velocity of the baffle decreases due to the boundary condition. The interaction increases again, resulting in another peak impact force. After repeated impact and separation several times, the velocities of the boulder and the impacted part of the baffle tend to be consistent gradually. This explains why the impact force fluctuates drastically in this stage. Subsequently, in the stable stage, the impacted part of the baffle and the boulder move at almost the same velocity. The plastic deformation of the baffle develops steadily, and the impact force is relatively stable. In this stage, the impact energy of the boulder is gradually transformed into the plastic strain energy of the baffle. The impact energy is mainly dissipated in this stage. Then, with the decreasing velocity of the boulder and baffle, the impact force starts to decrease until the velocity is close to zero and the unload stage starts. The impact ends when the boulder rebounds and separates from the baffle. The impact force decreases to zero at the moment.

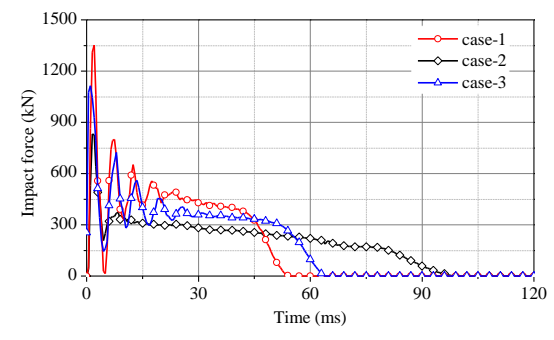

Fig. 10 Impact force-time history

For Case 1 and Case 3, there are several peaks during the first stage. For Case 1, the maximum peak force is $1350 \mathrm{kN}$ at $3.0 \mathrm{~ms}$. The stable stage lasts $21 \mathrm{~ms}$ and the stable impact force is about $400 \mathrm{kN}$. When $T=55 \mathrm{~ms}$, the impact force decreases to zero. For Case 2, there is only one significant peak force ( $\left.F_{\text {peak }}\right) 832 \mathrm{kN}$ when $T=2.0 \mathrm{~ms}$ during the peak stage. The stable stage lasts about $60 \mathrm{~ms}$, from $T=10 \mathrm{~ms}$ to $T=70 \mathrm{~ms}$. The stable impact force $\left(F_{\text {stable }}\right)$ is about $250 \mathrm{kN}$. When $T=99 \mathrm{~ms}$, the impact force decreases to zero. For Case 3, the maximum peak force is $1110 \mathrm{kN}$ at $2.0 \mathrm{~ms}$. The stable stage lasts about 25 $\mathrm{ms}$ and the stable impact force is about $350 \mathrm{kN}$. When $T=65 \mathrm{~ms}$, the impact force decreases to zero. The maximum impact forces and impact durations of the three cases show that the impact stiffness of Case 2 is the lowest, and that of Case 1 is the highest.

\subsubsection{Energy dissipating mode}

As shown in Fig. 11, for Case 1, the permanent displacements of the impact point and the monitor point are $181 \mathrm{~mm}$ and $290 \mathrm{~mm}$, respectively. The displacement of the monitor point located at the top of the baffle is much larger than that of the impact point. From the development of deformation as shown in Fig.12 (a), the buckling of the compression flange at the bottom occurs firstly when $T=11 \mathrm{~ms}$. Then, the buckling of the web in compression at the bottom occurs when $T=30 \mathrm{~ms}$. As the impact continues, the plastic deformation of the flange and the web at the bottom gradually increases until the boulder rebounds. The deformation of the baffle impacted by the boulder is mainly concentrated on the compression flange and web at the bottom of the baffle.

For Case 2, the permanent displacements of the impact point and the monitor point (Fig. 7) are $292 \mathrm{~mm}$ and $218 \mathrm{~mm}$, respectively. The permanent displacement of the impact point is much larger than that of the monitor point located at the top of the baffle, which means the deformation of the baffle is local. From the development of deformation as shown in Fig. 12(b), the buckling of the web at the impact area occurs soon after the impact happens when $T=9.0 \mathrm{~ms}$. As the impact continues, the plastic deformation of the web gradually increases until the boulder rebounds. The deformation of the baffle impacted by the boulder is mainly concentrated on the impact area, derived from the buckling of the web subjected to local compression.

For Case 3, the permanent displacements of the impact point and the monitor point are $204 \mathrm{~mm}$ and $206 \mathrm{~mm}$, respectively. The displacements of the two points are practically the same, which means the deformation of the baffle above the impact point is almost the overall translation. From the development of deformation as shown in Fig. 12(c), the web below the impact point demonstrates obvious shear buckling characteristic when $T=14.5 \mathrm{~ms}$. As the impact continues, the plastic deformation of the web below the impact point gradually increases until the boulder rebounds. The deformation of the baffle impacted by the boulder is mainly concentrated on the area below the impact point, derived from the shear buckling of the web below the impact point.

From what has been discussed above, the energy dissipating modes can be classified into three major types according to the typical deformation characteristics, namely: a) flexural, b) local compression buckling and c) shear buckling.



Fig. 11 Displacement-time history

\subsubsection{Energy-dissipating characteristic}

The internal energies of the flange and the web of each case after the boulder rebounded and separated from the baffle were extracted from the simulations and shown in Fig. 13. The internal energy of the flange and web are denoted as $E_{\mathrm{f}}$ and $E_{\mathrm{w}}$, respectively. The summation of $E_{\mathrm{f}}$ and $E_{\mathrm{w}}$ is the energy dissipated by the baffle denoted as $E_{\mathrm{b}}$. For Case $1, E_{\mathrm{f}}, E_{\mathrm{w}}$ and $E_{\mathrm{b}}$ are $61.8 \mathrm{~kJ}, 34.1 \mathrm{~kJ}$ and $95.9 \mathrm{~kJ}$, respectively. For Case $2, E_{\mathrm{f}}, E_{\mathrm{w}}$ and $E_{\mathrm{b}}$ are $17.9 \mathrm{~kJ}$, $79.6 \mathrm{~kJ}$ and $97.5 \mathrm{~kJ}$, respectively. For Case $3, E_{\mathrm{f}}, E_{\mathrm{w}}$ and $E_{\mathrm{b}}$ are $17.1 \mathrm{~kJ}, 80 \mathrm{~kJ}$ and $97.1 \mathrm{~kJ}$, respectively. It can be seen that the energies dissipated by the baffles all are slightly less than the impact energy $100 \mathrm{~kJ}$. The main reason lies in the energy dissipated by friction and the kinetic energy of the rebounded boulder. For Case 2 and Case 3, the web of the baffle dissipated almost $80 \%$ of the impact energy, which means the web is the major energy dissipation component. For Case 1, the major energy dissipation component is the flange, which dissipated about $60 \%$ of the impact energy. The energy-dissipating characteristics are also consistent with the deformation characteristics as shown in Fig. 12. It also shows that both the flange and the web can be the major energy dissipation component of an H-shaped baffle. 

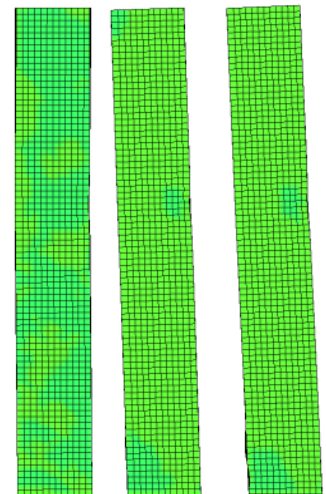

$t=3.0 \mathrm{~ms} \quad t=6.5 \mathrm{~ms}$

$t=8.5 \mathrm{~ms}$
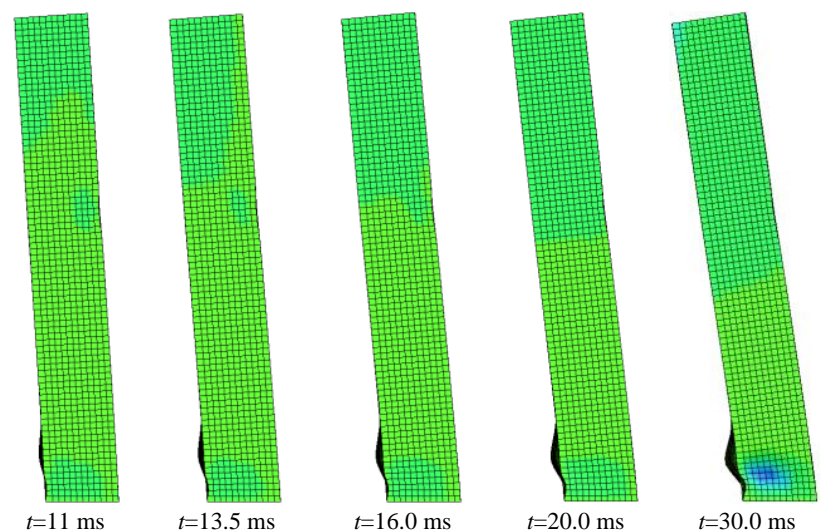

(a) Case-1
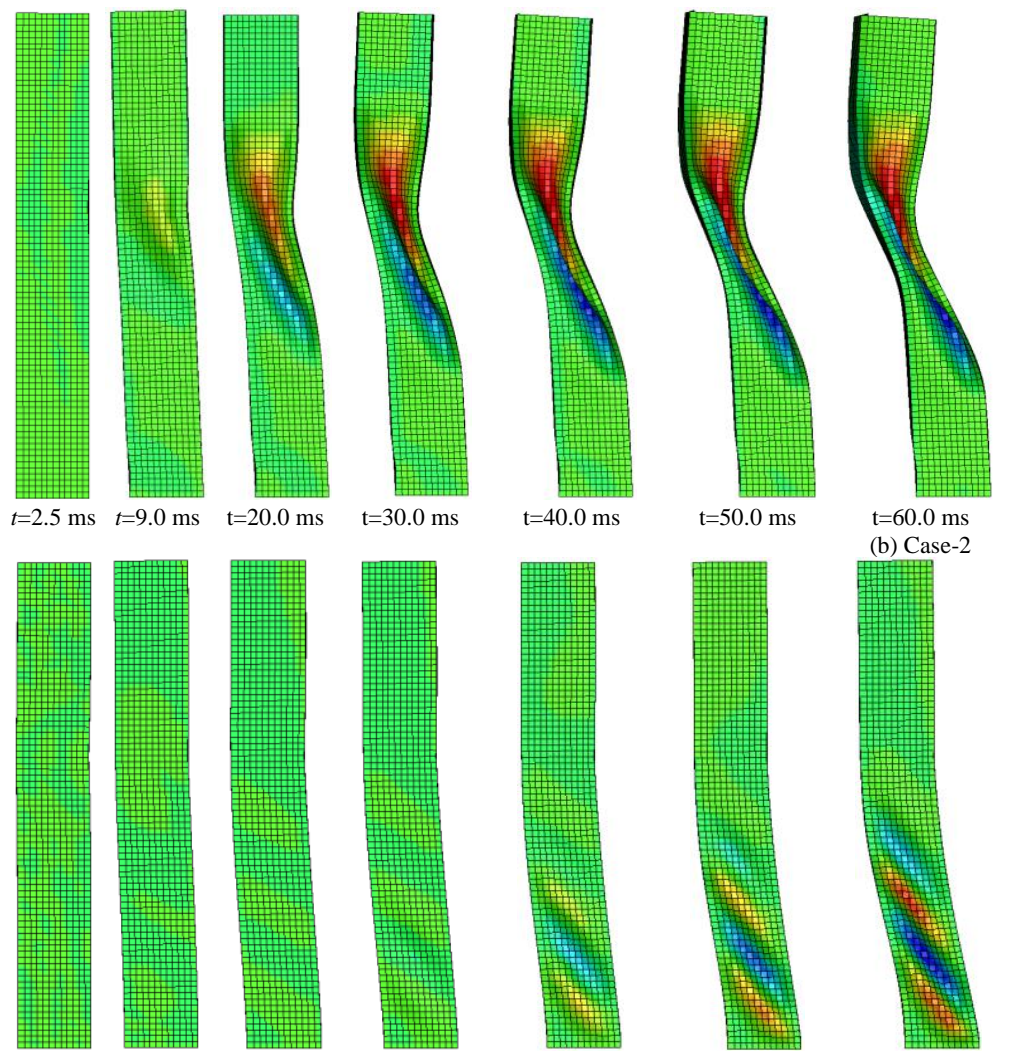

$t=9.0 \mathrm{~ms}$

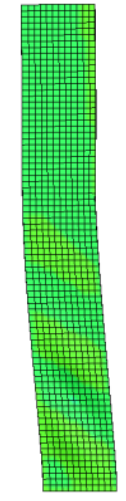

$t=11.5 \mathrm{~ms}$

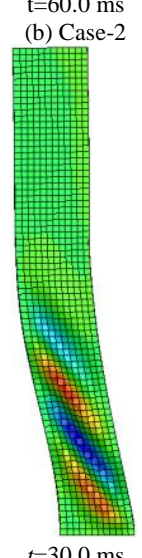

$t=30.0 \mathrm{~ms}$

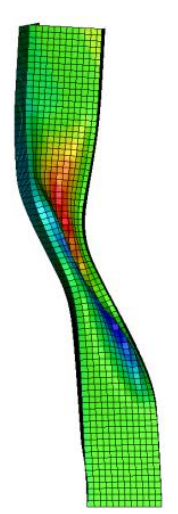

$\mathrm{t}=70.0 \mathrm{~ms}$

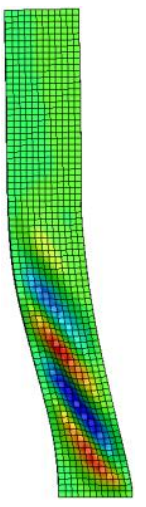

$t=40.0 \mathrm{~ms}$

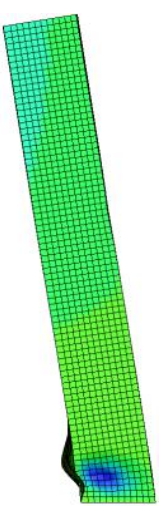

$t=40.0 \mathrm{~ms}$


$t=50.0 \mathrm{~ms}$

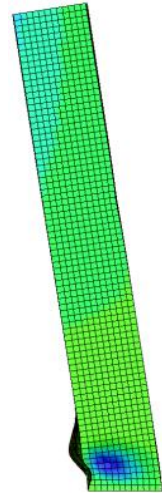

$t=50.0 \mathrm{~ms}$

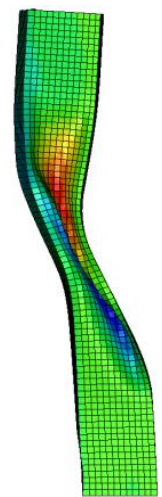

$\mathrm{t}=90.0 \mathrm{~ms}$

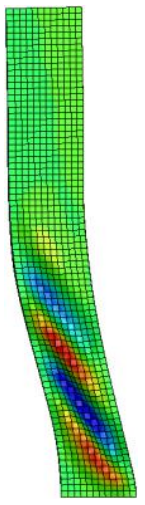

$t=60.0 \mathrm{~ms}$

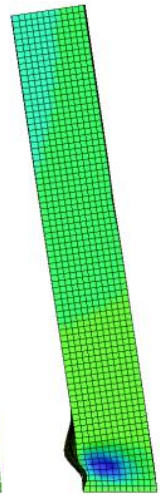

$t=55.0 \mathrm{~ms}$

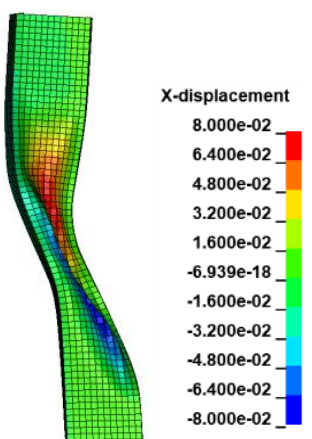

$\mathrm{t}=99.0 \mathrm{~ms} \quad$ legend



$t=65.0 \mathrm{~ms}$

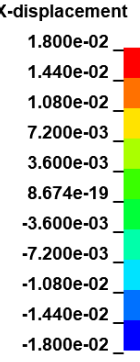

legend

Fig. 12 Deformation development of baffles

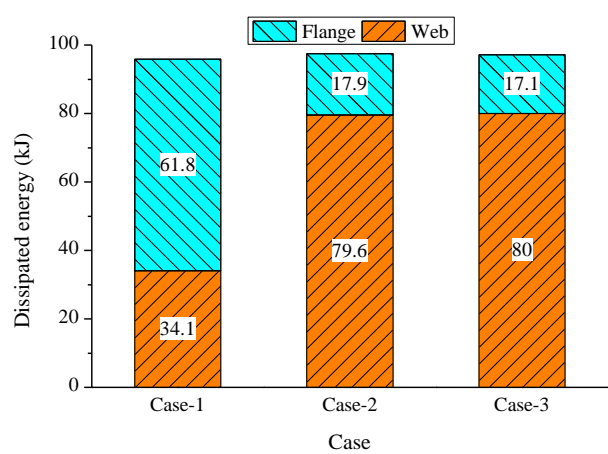

Fig. 13 Energy-dissipating characteristic

\subsubsection{Energy dissipating efficiency}

The energy dissipated per unit area denoted as $\lambda\left(\mathrm{J} / \mathrm{mm}^{2}\right)$ is defined to evaluate the energy dissipating efficiency of a baffle, and $\lambda$ is calculated by Eq. (3):

where $s_{\mathrm{b}}$ is the cross-section area of the baffle $\left(\mathrm{mm}^{2}\right) . \lambda$ can also be used to evaluate the energy dissipating efficiency of the flange or the web of an $\mathrm{H}$ shaped baffle when $E_{\mathrm{b}}$ is substituted by $E_{\mathrm{f}}$ or $E_{\mathrm{w}}$ and $s_{b}$ is substituted by the cross-section area of the flange or the web.

Table 4 shows the energy dissipating efficiency of these baffles, as well as that of the flange and web. It can be seen that, as far as the baffle is concerned, the highest energy dissipating efficiency is Case 2, which is 11 . The lowest energy dissipating efficiency is Case 3, which is only 5.9. The former is about twice as much as the latter. It indicates that the energydissipating mode represented by Case 2, which is local compression buckling as discussed in Section 4.3.2, is the most efficient. The energy dissipating efficiencies of the flange of these cases all are below 10, and the lowest is only 1.1 in Case 3. But the energy dissipating efficiency of the web is much higher than that of the flange. In Case 2 and Case 3, the energy dissipating efficiencies of the web both are about 50. Even the lowest dissipating efficiency of the web in the three cases is also larger than 10. It indicates that the web and flange of an $\mathrm{H}$-shaped baffle are the effective and ineffective components for energy dissipation, respectively. The web of an $\mathrm{H}$-shaped baffle is recommended to be designed as the major energy dissipation component of an $\mathrm{H}$-shaped baffle. 
Table 4

Energy dissipating efficiency

\begin{tabular}{|c|c|c|c|c|c|c|c|c|c|}
\hline & $E_{\mathrm{b}}(\mathrm{J})$ & $E_{\mathrm{f}}(\mathrm{J})$ & $E_{\mathrm{w}}(\mathrm{J})$ & $s_{\mathrm{b}}\left(\mathrm{mm}^{2}\right)$ & $s_{\mathrm{f}}\left(\mathrm{mm}^{2}\right)$ & $s_{\mathrm{w}}\left(\mathrm{mm}^{2}\right)$ & $\lambda_{\mathrm{b}}\left(\mathrm{J} / \mathrm{mm}^{2}\right)$ & $\lambda_{\mathrm{f}}\left(\mathrm{J} / \mathrm{mm}^{2}\right)$ & $\lambda_{\mathrm{w}}\left(\mathrm{J} / \mathrm{mm}^{2}\right)$ \\
\hline case-1 & $9.59 \times 10^{4}$ & $6.18 \times 10^{4}$ & $3.41 \times 10^{4}$ & $1.05 \times 10^{4}$ & $7.20 \times 10^{3}$ & $3.31 \times 10^{3}$ & 9.1 & 8.6 & 10.3 \\
\hline case-2 & $9.75 \times 10^{4}$ & $1.79 \times 10^{4}$ & $7.96 \times 10^{4}$ & $8.86 \times 10^{3}$ & $7.20 \times 10^{3}$ & $1.66 \times 10^{3}$ & 11.0 & 2.5 & 48.1 \\
\hline case-3 & $9.71 \times 10^{4}$ & $1.71 \times 10^{4}$ & $8.01 \times 10^{4}$ & $1.65 \times 10^{4}$ & $1.50 \times 10^{4}$ & $1.50 \times 10^{3}$ & 5.9 & 1.1 & 53.3 \\
\hline
\end{tabular}

\section{Design recommendation}

As discussed above, the energy dissipating modes of an $\mathrm{H}$-shaped baffle subjected to the impact of a boulder can be divided into three types, and local compression buckling is the most efficient. Considering the fact that the mode of energy dissipation is mainly determined by $\gamma_{\mathrm{f}}$ and $\gamma_{\mathrm{w}}$, a total of 34 impact cases divided into 4 groups with different cross-sectional properties (Table 5) were simulated to find out the boundary value in this section. In these cases, the depth and width of the cross-section were both fixed to $300 \mathrm{~mm}$. From Group 1 to Group 4, the thicknesses of the webs were fixed to $4 \mathrm{~mm}, 6 \mathrm{~mm}$, $8 \mathrm{~mm}$ and $10 \mathrm{~mm}$, respectively. In each group, the thicknesses of the flanges ranged from $6 \mathrm{~mm}$ to $25 \mathrm{~mm}$. The mass of the boulder was fixed to $2000 \mathrm{~kg}$. In order to ensure that the boulders were all stopped by these baffles and the baffles deformed significantly, the initial velocities of the boulders were different in these cases. For these cases named G-1-1 G-1-10 and G-2-1, the impact velocity of the boulder was $7.07 \mathrm{~m} / \mathrm{s}$, which means the impact energy was $50 \mathrm{~kJ}$. For these cases in Group 2 and Group 3 except for G-2-1, the impact velocity of the boulder was $10.0 \mathrm{~m} / \mathrm{s}$ and the impact energy was $100 \mathrm{~kJ}$. For these cases in Group 4, the impact velocity of the boulder was $14.1 \mathrm{~m} / \mathrm{s}$ and the impact energy was $200 \mathrm{~kJ}$.

The simulated results show that with the increasing of $\gamma_{\mathrm{w}} / \gamma_{\mathrm{f}}$, the energy dissipating mode is transformed from flexural (Type 1) to shear buckling (Type 3) gradually as a whole. But for the baffle with different thicknesses of the webs, the difference of the boundary values of the three energy dissipating modes is significant.

Table 5

Parametric study

\begin{tabular}{|c|c|c|c|c|c|c|c|c|c|}
\hline \multicolumn{2}{|c|}{ Case } & \multicolumn{4}{|c|}{ Cross-section properties } & \multicolumn{3}{|c|}{ Impact properties } & \multirow{2}{*}{ Energy dissipating mode } \\
\hline & & Size & $\gamma_{\mathrm{f}}$ & $\gamma_{\mathrm{w}}$ & $\gamma_{\mathrm{w}} \gamma_{\mathrm{f}}$ & $m(\mathrm{~kg})$ & $v_{0}(\mathrm{~m} / \mathrm{s})$ & $E_{0}(\mathrm{~kJ})$ & \\
\hline \multirow{10}{*}{ Group 1} & G-1-1 & $\mathrm{H} 300 \times 300 \times 4 \times 6$ & 25.0 & 72.0 & 2.9 & 2000 & 7.07 & 50 & Type 2 \\
\hline & G-1-2 & $\mathrm{H} 300 \times 300 \times 4 \times 8$ & 18.8 & 71.0 & 3.8 & 2000 & 7.07 & 50 & Type 2 \\
\hline & G-1-3 & $\mathrm{H} 300 \times 300 \times 4 \times 10$ & 15.0 & 70.0 & 4.7 & 2000 & 7.07 & 50 & Type 2 \\
\hline & G-1-4 & $\mathrm{H} 300 \times 300 \times 4 \times 12$ & 12.5 & 69.0 & 5.5 & 2000 & 7.07 & 50 & Type 2 \\
\hline & G-1-5 & $\mathrm{H} 300 \times 300 \times 4 \times 14$ & 10.7 & 68.0 & 6.3 & 2000 & 7.07 & 50 & Type 2 \\
\hline & G-1-6 & $\mathrm{H} 300 \times 300 \times 4 \times 16$ & 9.4 & 67.0 & 7.1 & 2000 & 7.07 & 50 & Type 2 \\
\hline & G-1-7 & $\mathrm{H} 300 \times 300 \times 4 \times 18$ & 8.3 & 66.0 & 7.9 & 2000 & 7.07 & 50 & Type 2 \\
\hline & G-1-8 & $\mathrm{H} 300 \times 300 \times 4 \times 20$ & 7.5 & 65.0 & 8.7 & 2000 & 7.07 & 50 & Type 2 \\
\hline & G-1-9 & $\mathrm{H} 300 \times 300 \times 4 \times 22$ & 6.8 & 64.0 & 9.4 & 2000 & 7.07 & 50 & Type 2 \\
\hline & G-1-10 & H $300 \times 300 \times 4 \times 25$ & 6.0 & 62.5 & 10.4 & 2000 & 7.07 & 50 & Type 3 \\
\hline \multirow{9}{*}{ Group 2} & G-2-1 & $\mathrm{H} 300 \times 300 \times 6 \times 8$ & 18.8 & 47.3 & 2.5 & 2000 & 7.07 & 50 & Type 1 \\
\hline & G-2-2 & $\mathrm{H} 300 \times 300 \times 6 \times 10$ & 15.0 & 46.7 & 3.1 & 2000 & 10.0 & 100 & Type 1 \\
\hline & G-2-3 & $\mathrm{H} 300 \times 300 \times 6 \times 12$ & 12.5 & 46.0 & 3.7 & 2000 & 10.0 & 100 & Type 2 \\
\hline & G-2-4 & $\mathrm{H} 300 \times 300 \times 6 \times 14$ & 10.7 & 45.3 & 4.2 & 2000 & 10.0 & 100 & Type 2 \\
\hline & $\mathrm{G}-2-5$ & $\mathrm{H} 300 \times 300 \times 6 \times 16$ & 9.4 & 44.7 & 4.8 & 2000 & 10.0 & 100 & Type 3 \\
\hline & G-2-6 & H $300 \times 300 \times 6 \times 18$ & 8.3 & 44.0 & 5.3 & 2000 & 10.0 & 100 & Type 3 \\
\hline & G-2-7 & H $300 \times 300 \times 6 \times 20$ & 7.5 & 43.3 & 5.8 & 2000 & 10.0 & 100 & Type 3 \\
\hline & G-2-8 & $\mathrm{H} 300 \times 300 \times 6 \times 22$ & 6.8 & 42.7 & 6.3 & 2000 & 10.0 & 100 & Type 3 \\
\hline & G-2-9 & H $300 \times 300 \times 6 \times 25$ & 6.0 & 41.7 & 6.9 & 2000 & 10.0 & 100 & Type 3 \\
\hline \multirow{6}{*}{ Group 3} & G-3-1 & $\mathrm{H} 300 \times 300 \times 8 \times 10$ & 15.0 & 35.0 & 2.3 & 2000 & 10.0 & 100 & Type 1 \\
\hline & G-3-2 & $\mathrm{H} 300 \times 300 \times 8 \times 12$ & 12.5 & 34.5 & 2.8 & 2000 & 10.0 & 100 & Type 1 \\
\hline & G-3-3 & Н $300 \times 300 \times 8 \times 14$ & 10.7 & 34.0 & 3.2 & 2000 & 10.0 & 100 & Type 1 \\
\hline & G-3-4 & $\mathrm{H} 300 \times 300 \times 8 \times 16$ & 9.4 & 33.5 & 3.6 & 2000 & 10.0 & 100 & Type 1 \\
\hline & G-3-5 & H $300 \times 300 \times 8 \times 18$ & 8.3 & 33.0 & 4.0 & 2000 & 10.0 & 100 & Type 3 \\
\hline & G-3-6 & Н $300 \times 300 \times 8 \times 20$ & 7.5 & 32.5 & 4.3 & 2000 & 10.0 & 100 & Type 3 \\
\hline
\end{tabular}

For Group 1, the thickness of the web of these cases was $4 \mathrm{~mm}$, and the energy dissipating modes were all local compression buckling (Type 2) when the $\gamma_{\mathrm{w}} / \gamma_{\mathrm{f}}$ ranged from 2.9 to 10.4. Only when the thickness of the flange was increased to $25 \mathrm{~mm}$ and the $\gamma_{\mathrm{w}} / \gamma_{\mathrm{f}}$ was 10.4 , the energy dissipating mode was transformed to Type 3; Type 1 did not appear even when $\gamma_{\mathrm{w}} / \gamma_{\mathrm{f}}=2.9$. Therefore, for this group, it can be summarized that there are only two energy dissipating modes, Type 2 and Type 3, and the boundary value is 9.4.

For Group 2, the thickness of the web of these cases was $6 \mathrm{~mm}$, and all the three types of energy dissipating modes appeared when $\gamma_{\mathrm{w}} / \gamma_{\mathrm{f}}$ ranged from 2.5 to 6.9. The boundary values of $\gamma_{\mathrm{w}} / \gamma_{\mathrm{f}}$ between Type 1 and Type 2, Type 2 and Type 3 were 3.7 and 4.2 , respectively.

For Group 3, the thickness of the web of these cases was $8 \mathrm{~mm}$, and Type 2 did not occur. The energy dissipating mode was transformed from Type 1 when $\gamma_{\mathrm{w}} / \gamma_{\mathrm{f}}=3.6$ to Type 3 when $\gamma_{\mathrm{w}} / \gamma_{\mathrm{f}}=4.0$. Therefore, for this group, the boundary value of these types is between 3.6 and 4.0.

For Group 4, the thickness of the web of these cases was $10 \mathrm{~mm}$, and Type 2 did not occur either. The energy dissipating mode was transformed from Type 1 when $\gamma_{\mathrm{w}} / \gamma_{\mathrm{f}}=3.5$ to Type 3 when $\gamma_{\mathrm{w}} / \gamma_{\mathrm{f}}=3.8$. Therefore, for this group, the boundary value of these types is between 3.5 and 3.8 .

Therefore, considering the energy dissipating efficiency of a baffle, the thickness of the web, denoted as $t_{\mathrm{w}}$, is suggested to be $4 \mathrm{~mm}$ or $6 \mathrm{~mm}$. For $t_{\mathrm{w}}=4 \mathrm{~mm}$, when $\gamma_{\mathrm{w}} / \gamma_{\mathrm{f}} \leq 9.4$, it can ensure that the energy dissipating mode is Type 2. For $t_{\mathrm{w}}=6 \mathrm{~mm}$, when $3.7 \leq \gamma_{\mathrm{w}} / \gamma_{\mathrm{f}} \leq 4.2$, it can also ensure that the energy dissipating mode is Type 2 . 


\begin{tabular}{|c|c|c|c|c|c|c|c|c|c|}
\hline & G-3-7 & $\mathrm{H} 300 \times 300 \times 8 \times 22$ & 6.8 & 32.0 & 4.7 & 2000 & 10.0 & 100 & Type 3 \\
\hline & G-3-8 & $\mathrm{H} 300 \times 300 \times 8 \times 25$ & 6.0 & 31.3 & 5.2 & 2000 & 10.0 & 100 & Type 3 \\
\hline \multirow{7}{*}{ Group 4} & G-4-1 & $\mathrm{H} 300 \times 300 \times 10 \times 12$ & 12.5 & 27.6 & 2.2 & 2000 & 14.1 & 200 & Type 1 \\
\hline & G-4-2 & $\mathrm{H} 300 \times 300 \times 10 \times 14$ & 10.7 & 27.2 & 2.5 & 2000 & 14.1 & 200 & Type 1 \\
\hline & G-4-3 & $\mathrm{H} 300 \times 300 \times 10 \times 16$ & 9.4 & 26.8 & 2.9 & 2000 & 14.1 & 200 & Type 1 \\
\hline & G-4-4 & $\mathrm{H} 300 \times 300 \times 10 \times 18$ & 8.3 & 26.4 & 3.2 & 2000 & 14.1 & 200 & Type 1 \\
\hline & G-4-5 & $\mathrm{H} 300 \times 300 \times 10 \times 20$ & 7.5 & 26.0 & 3.5 & 2000 & 14.1 & 200 & Type 1 \\
\hline & G-4-6 & $\mathrm{H} 300 \times 300 \times 10 \times 22$ & 6.8 & 25.6 & 3.8 & 2000 & 14.1 & 200 & Type 3 \\
\hline & $\mathrm{G}-4-7$ & $\mathrm{H} 300 \times 300 \times 10 \times 25$ & 6.0 & 25.0 & 4.2 & 2000 & 14.1 & 200 & Type 3 \\
\hline
\end{tabular}

Note: Type 1 - flexural type, Type 2 - local compression buckling type, Type 3 - shear buckling type

\section{Conclusions}

Flexible barriers have been extensively adopted for the mitigation of rockfalls. Steel posts are the important compression members to ensure the integrity of interception structure and the function of the system. Due to the random trajectories of rockfalls, steel posts may be impacted by boulders directly and the impact scenario may result in the failure of the post and even the collapse of the system. In this paper, steel baffles were proposed to install in front of steel posts of flexible barrier systems to protect the posts. Numerical simulations were carried out to investigate the energy-dissipating modes and control method of $\mathrm{H}$-shaped steel baffles subjected to boulder impact. The key findings from this study are summarized as follows:

1. Steel baffles are proposed to be an additional structural countermeasure installed in front of the posts of flexible barriers to protect the posts from boulder impact. The principle of the baffle mainly lies in the following two aspects: a) dissipate the impact energy of the boulder; b) change the trajectory of the boulder.

2. Three typical energy-dissipating modes, i.e., a) flexural, b) local compression buckling and c) shear buckling, are observed based on the numerical simulation results.

3. Energy dissipating efficiency is defined as the energy dissipated per unit area to evaluate the efficiency of a baffle. The local compression buckling mode is the most efficient.

4. With the increasing of ratio $\gamma_{\mathrm{w}} / \gamma_{\mathrm{f}}$, the energy dissipating mode is transformed from Type 1 to Type 3 gradually. However, for the baffle with different thicknesses of the webs, the boundary values of the three energy dissipating modes differ widely. The thickness of the web of an $\mathrm{H}$-shaped baffle is suggested to be $4 \mathrm{~mm}$ and $6 \mathrm{~mm}$ for the rated dissipating energy of 50 $\mathrm{kJ}$ and $100 \mathrm{~kJ}$, respectively. For $t_{\mathrm{w}}=4 \mathrm{~mm}$ or $t_{\mathrm{w}}=6 \mathrm{~mm}$, when $\gamma_{\mathrm{w}} / \gamma_{\mathrm{f}} \leq 9.4$ or 3.7 $\leq \gamma_{\mathrm{w}} / \gamma_{\mathrm{f}} \leq 4.2$, respectively, the energy dissipating modes of the baffles is ensured to be the local compression buckling (Type 2).

Besides, it should be clarified that the findings from this paper are based on a specific height, width and depth of $\mathrm{H}$-shaped baffles subjected to a specific impact scenario. Further studies on more factors affecting the

\section{References}

[1] Zhao L., Yu Z.X., Liu Y.P. He J.W. and Zhao S.C., "Numerical simulation of responses of flexible rockfall barriers under impact loading at different positions", Journal of Constructional Steel Research, 167, 2020.

[2] Yu Z.X., Zhao L., Liu Y.P., Zhao S.C., Xu H. and Chan S.L., "Studies on flexible rockfall barriers for failure modes, mechanisms and design strategies: a case study of Western China", Landslides, 16, 347-362, 2019.

[3] Qi X., Yu Z.X., Zhao L., Xu H. and Zhao S.C., "A new numerical modelling approach for flexible rockfall protection barriers based on failure modes", Advanced Steel Construction, $14,479-495,2018$.

[4] Xu H., Gentilini C., Yu Z.X., Qi X. and Zhao S.C., "An energy allocation-based design approach for flexible rockfall protection barriers", Engineering Structures, 173, 831-852, 2018.

[5] Kwan J.S.H., Chan S.L., Cheuk J.C.Y. and Koo R.C.H., "A case study on an open hillside landslide impacting on a flexible rockfall barrier at Jordan Valley, Hong Kong", Landslides, $11,1037-1050,2014$.

[6] Gentilini C., Gottardi G., Govoni L., Mentani A. and Ubertini F., "Design of falling rock protection barriers using numerical models", Engineering Structures, 50, 96-106, 2013.

[7] EOTA-European Organization for Technical Assessment. Falling rock protection kits EAD 340059-00-0106 [S]. 2018.

[8] Qi X., Mechanics performance of passive flexible protection structure, Chengdu, Southwest Jiaotong University, 2013. (In Chinese)

[9] Castanon-Jano L., Blanco-Fernandez E., Castro-Fresno D. and Ballester-Muñoz F., "Energy dissipating devices in falling rock protection barriers", Rock Mechanics and Rock Engineering, 50, 603-619, 2017.

[10] Fuller R.B., Tensile-Integrity Structures, US Patent, 3063521, 1962.

[11] Biagi V.D., Marchelli M. and Peila D., "Reliability analysis and partial safety factors approach for rockfall protection structures", Engineering Structures, 213,110553, 2020.

[12] Zhao L., He J.W., Yu Z.X., Liu Y.P. and Chan S.L., "Coupled numerical simulation of a flexible barrier impacted by debris flow with boulders in front", Landslides, 17, 2723-2736, dynamic response of a baffle are recommended.

\section{Acknowledgements}

The authors are grateful for the support provided by the National Key Research and Development Program of China (Grant No. 2018YFC 1505405), the National Natural Science Foundation of China (Grant No. 51678504), the Department of Science and Technology of Sichuan Province (Grant No. 2018JY0029, 2020YJ0263) and the Fundamental Research Funds for the Central Universities (Grant No. 2682020CX62), and Geological Survey Project of CGS (Grant No. DD20190637).

\section{Appendix A}

A.1 Notations

\begin{tabular}{llll}
\hline$m_{0}$ & Mass & $E$ & Elasticity modulus \\
$H_{0}$ & Release height & $v$ & Poisson ratio \\
$E_{0}$ & Impact energy & $t$ & Thickness \\
$v_{0}$ & Initial impact velocity & $b$ & Width \\
$\sigma_{\mathrm{yd}}$ & Dynamic yield stress & $\gamma_{\mathrm{f}}$ & Flange width-thickness ratio \\
$\sigma_{\mathrm{ys}}$ & Static yield stress & $\gamma_{\mathrm{w}}$ & Web height-thickness ratio \\
$C$ & Dynamic strain rate parameter & $F_{\text {stable }}$ & Stable impact force \\
$P$ & Dynamic strain rate parameter & $E_{\mathrm{f}}$ & Internal energy of flange \\
$F_{\text {peak }}$ & Peak impact force & $E_{\mathrm{w}}$ & Internal energy of web \\
$F_{\text {plateau }}$ & Plateau impact force & $E_{\mathrm{b}}$ & Dissipated energy \\
$T$ & Duration of impact force & $\lambda$ & Energy dissipated per unit area \\
$\chi$ & Constraint coefficient & $s_{\mathrm{b}}$ & Cross-section area \\
$k$ & Buckling coefficient & & \\
\hline
\end{tabular}

2020.

[13] Brunet G., Giacchetti G. and Grimod A., "Rockfall barrier behavior under multiple impact events", 64th highway geology symposium, New Hampshire, USA, 9-12 September 2013.

[14] Scarpato D.J., Ingraham P.C., Group R.P., Shevlin T.D. "Deflection as a Positive Attribute", Geostrata May/June,61-66, 2020.

[15] Wang Y., "Lessons learned from the "5.12" Wenchuan Earthquake: evaluation of earthquake performance objectives and the importance of seismic conceptual design principles", Earthquake Engineering and Engineering Vibration, 7, 255-262, 2008.

[16] Shakir A.S., Guan Z.W. and Jones S.W., "Lateral impact response of the concrete fille steel tube columns with and without CFRP strengthening", Engineering Structures, 116, $148-162,2016$.

[17] Pei C. and Wang R., "Parametric Analysis of the Dynamic Response of Hot-Rolled HShaped Steel Beam under Lateral Impact Load", Applied Mechanics and Materials, 215216, 998-1002, 2012.

[18] Al-Thairy H. and Wang Y.C., "A numerical study of the behaviour and failure modes of axially compressed steel columns subjected to transverse impact", International Journal of Impact Engineering, 38, 732-744, 2011.

[19] Zhao H., Wang R, Li Q.M., Wu H., Hou C.C. and An G., "Experimental and numerical investigation on impact and post-impact behaviours of H-shaped steel members", Engineering Structures, 216, 2020.

[20] Bambach M.R., Jama H., Zhao X.L. and Grzebiets R.H., "Hollow and concrete filled stee hollow sections under transverse impact loads", Engineering Structures, 30, 2859-70, 2008.

[21] Han L.H., Yao G.H. and Tao Z. Performance of concrete filled thin-walled steel tubes under pure torsion. Thin-Walled Struct 2007; 45:24-36.

[22] Cowper G.R. and Symonds P.S., Strain-hardening and strain-rate effects in the impact loading of cantilever beams, Brown Univ, Providence Ri, 1957.

[23] Jones N., "Structural impact", Cambridge university press, 2011

[24] Hallquist J.O., "LS-DYNA theory manual", Livermore Software. Technol. Corp., 2006.

[25] GB 50017-2017. Standard for Design of Steel Structures. Beijing: China Architecture \& Building Press; 2017. 